\title{
EL CICLO CELULAR EN VEGETALES. Su estudio, importancia y aplicaciones.
}

\section{RESUMEN}

\begin{abstract}
Se presenta una gela para determinar la frecucacia y duración de cads fase del ciclo celuler y de todo el ciclo, as conso para ubicar el momento apropiado para la toma de muestras para investigaciones sobre contajes y marfologia cromosonica. Se describe uno de los metrodos utifizados para

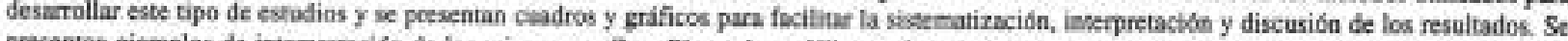
presentan ejemplos de inteperación ee los mismos en Zea Phasealus y Uhacus. Se presta especial atención a los factores que condicionan las modificaciones del cielo celular y la formación de poliploides, sefalando la importancia de este tipo de estudios y sus positelidades de aplicaciōn para la solución de peoblemes teóricos (ubicación sistemaitica, esclarecianiente de la filogenia), as ( como con fines pricticos (compectibilidad para los crazamienas, evaluación de la velocidad de crecimiento).

PALABRAS CLAVE: Vegetales, ciclo celular, poliploidización
\end{abstract}

\section{SUMMARY}

This paper presents a guide to determine the frequency and duration of each cellular eyele phase and of the whole cycle as well as to locate the apropisee time for sampling in arder to make researches on eousting and morpbology of chromosomes. One of the methods ased to develop this type od study is described and tables and grnphics are included in discussion of the resules. Examples of interpectation are presemted in Zea, Phoseche and Unucus. The paper focuses on the fastoes conditioning the changes of the cellular cycle and the formution of polyploids. Pighlighting the significance of this type of atodies and its possibilities of aptication for the solusion of theonctal problems (systematic locasion, clearing of phylogenetics) and for practical purposes as well (compatibitity for crussing-over, assessment of the groweth rate)

KEY WORDS: Vegetables, vell cycie, polyploidizzsion.

\section{INTRODUCCION}

El número y morfología de los cromosomas de los organismos eucariontes se estudian con mayor facilidad durante el periodo de su mayor condensación, la metafase mitctica. Sin embargo, esta es sólo una etapa, por lo general bastante breve, del ciclo celular; es decir, del ciclo de transformaciones de la célula ligado al proceso de su reproducción. Para desarrollar análisis cariotípicos a nive」 de contajes y evidenciación de la morfología cromosómica es indispensable ubicar el preciso momento en el cual los cromosomas presentan su mayor grado de condensación. Este periodo suele durar solo algunos minutos y depende de factores genéticos y ambientales. El estudio del ciclo celular nos permite eliminar el factor del azar y utilizar criterios objetivos para la toma de las muestras. (Del Campo, 1988; Smínov, 1991).

Sabemos que el ciclo celular no siempre termina con la división celular y que su regulación genética condiciona que cada una de las fases que lo conforman exija de una transcripción y do la sintesis de proteínas especificas (Van't Hoff, 1973). Por ello, el estudio del proceso puede ayudar a esclarecer las causas que determinan el importante rol de la poliploidía en el proceso de diversificación de las especies propias de zonas montañosas, como es el caso de las rafices y tuberosas andinas, asi como los mecanismos de formación de poliploides. También puede coadyuvar a esclarecer las causas de la divergencia de reportes en cuanto a números cromosómicos en estas especies ( $y$ la falta de regularidad en la distribución de estos nümeros), así como de la variación somaclonal observada en algunos cultivos reproducidos in vitro (Cárdenas \& Hawkes, 1948; Bolkhovskikh et, al. 1969: Molina \& Naranjo, 1987: Talledo, 1991; Talledo et. al. 1993; Larkka et al. 1992).

\section{ANTECEDENTES}

\section{el CiClo CELUlar EN VEgetales: SU ESTUDIO, IMPORTANCIA Y APLICACIONES. EL CICLO CELULAR: GENERALIDADES.}

La mayor parte de nuestros conocimientos acerca de la morfología de los cromosomas de los organismos eucariotes se basa en resultados obtenidos durante el periodo de su mayor condensación, la metafase mitótica. 
Sin embargo, la metafase es sólo una etapa, por lo general bastante breve, del ciclo celular (Talledo et al., 1993).

Como sabemos, el ciclo celular es el mecanismo universal de reproducción de las células eucariotes cuyo evento principal es la reproducción y duplicación del número de cromosomas, siendo la mitosis el mecanismo de división de los cromosomas, del núcleo y de toda la célula. Durante la mitosis se observa la destrucción de la membrana nuclear y la formación del huso acromático, que garantiza la distribución equitativa de los cromosomas (cromátides) espiralizados, y previamente duplicados, entre las células hijas.

El ciclo mitótico o cielo celular se extiende desde la formación de una célula, por división de la cellula madre, hasta su propia división en 2 células hijas. Esta unidad de tiempo tepresenta el ciclo de vida de una célula en proliferación y constituye la unidad de repetición en todo proceso de reproducción celular, siendo su principal caracteristica su naturaleza cíclica (Del Campo, 1988).

El ciclo celular del organismo en crecimiento comprende 2 etapas: la interfase, frecuentemente prolongada, y la mitosis, más breve (de $1 / 7$ a $1 / 10$ de todo el ciclo celular) , que consta de 4 fases (profase, metafase, anafase y telofase). Durante la interfase es posible observar un periodo $\mathrm{S}$ \% de sintesis, en el que se produce la replicación de los cromosomas, así como 2 períodos * $\mathrm{G} * \mathrm{G}_{1}$, anterior al período $* \mathrm{~S} *$ y $\mathrm{G}_{2}$. posterior a él. De manera que durante el período comprendido entre la telofase de un ciclo celular y la fase $\alpha \mathrm{S} \%$ de la interfase siguiente los núcleos presentan la cantidad de material genético propia de la especie, que frecuentemente corresponde al complemento diploide de cromosomas. Se ha establecido que durante la fase *S* esta cantidad aumenta paulatinamente y a partir del período $\mathrm{G}_{2}$ hasta la siguiente telofase es el doble. Así mismo, la duración del ciclo celular y de sus fases no es igual en los diferentes tipos de celulas de un organismo y varía significativamente durante la ontogénesis (Smírnov, 1991).

\section{CONTROL GENETICO DEL CICLO CELULAR}

Por otro lado, el ciclo celular no siempre termina con la división celular. Los periodos $G_{1}$ y $G_{2}$ no son solamente espacios de transicion al periodo eS* y a la mitosis, sino también espacios de decisión sobre si continúa o no la célula en ciclo de división o se separa temporal o definitivamente de él (Del Campo,1988). Sabemos que este cielo es regulado genéticamente: cada una de sus fases exige de una transcripción y de la sintesis de proteinas especificas (las proteínas de la división). Estas proteinas determinan el inicio del ciclo celular, de la replicación, de la finalización del período $S$, el paso de $G_{2}$ hacia la mitosis y el flujo de cada fase de esta última (Epilánova, 1973; Prescott, 1976). Algunas de estas proteinas aún no han sido identificadas, pero su efecto biológico se manifiesta claramente; por ejeruplo, el bloqueo de la síntesis protéica en un momento determinado del período $G_{1}$ (y sólo en ese momento) evita que las células pasen al periodo $\mathbf{S}$ (Brooks, 1977). Raoet al sugitieron en 1978 que la propia duración del período $\mathrm{G}_{\mathrm{f}}$ se determina por la velocidad de sintesis de los iniciadores y otros factores protéicos de la replicación. Se han encontrado más de 9 proteínas características sólo para el período $\mathrm{G}_{2}$ y no existen proteinas similares ni en otras fases del ciclo, ni en células bloqueadas en $\mathrm{O}_{2}$ por sustancias citostáticas (sustancias que paralizan el ciclo celular). Por ejemplo, luego de la fusion en cultivo sincronizado de células bloqueadas y células normales en $G_{2}$, las primeras iniciaron sus mitosis (Al-Bader et al. 1978). Por otro lado, las proteínas sintetizadas en el periodo $\mathrm{G}_{3}$ determunan también el curso de la citocinesis (Lasselain ef al. 1978).

La mitosis y sus resultados dependen funcionalmente del estado de los genes que controlan los procesos del ciclo celular. Esta relación puede ser llustrada coa células mutantes termolábiles respecto a la velocidad de su crecimiento. Por ejemplo, a temperaturas diferentes a la óptima, cuando crecen intensamente, estos mutantes presentan diferentes aberraciones de la mitosis: curso defectuoso de la profase con formación de estructuras atípicas, células detenidas en metafase con caracteristicas similares a C-mitosis (mitosis bloqueadas con colchicina); en ocasiones los procesos post-metafásicos se producen irregularmente y la membrana nuclear se forma alrededor de un grupo de cromosomas fusionados, dando lugar a células bi- y multinucleadas (Wang, 1974, 1976; Wissinger \& Wang, 1978). Asi mismo, se conocen líneas mutantes que presentan citocinesis termolábiles, aún cuando las demás fases y procesos permanezcan normales (Smith \& Wigglesworth. 1972; Shiomi \& Sato, 1978). Se considera que en los casos descritos mutan los genes que controlan la sintesis de las proteinas del huso acromático dando lugar a estructuras defectuosas y con protelnas incapaces de orientarse en condiciones que no sean las optimas.

Brodsky y Urivayeva (1970) clasifican los ciclos celulares incompletos en 2 tipos:

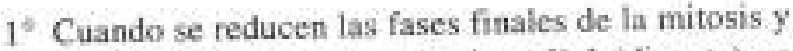
como resultado (de esta mitosis poliploidizante) se forma una célula con un complemento cromosb́nico duplicado y separado.

$2^{\text {n }}$ Cuando se reducen todas las fases de la mitosis (las células se bloquean en $\mathrm{G}_{2}$ ) y como resultado se forma 


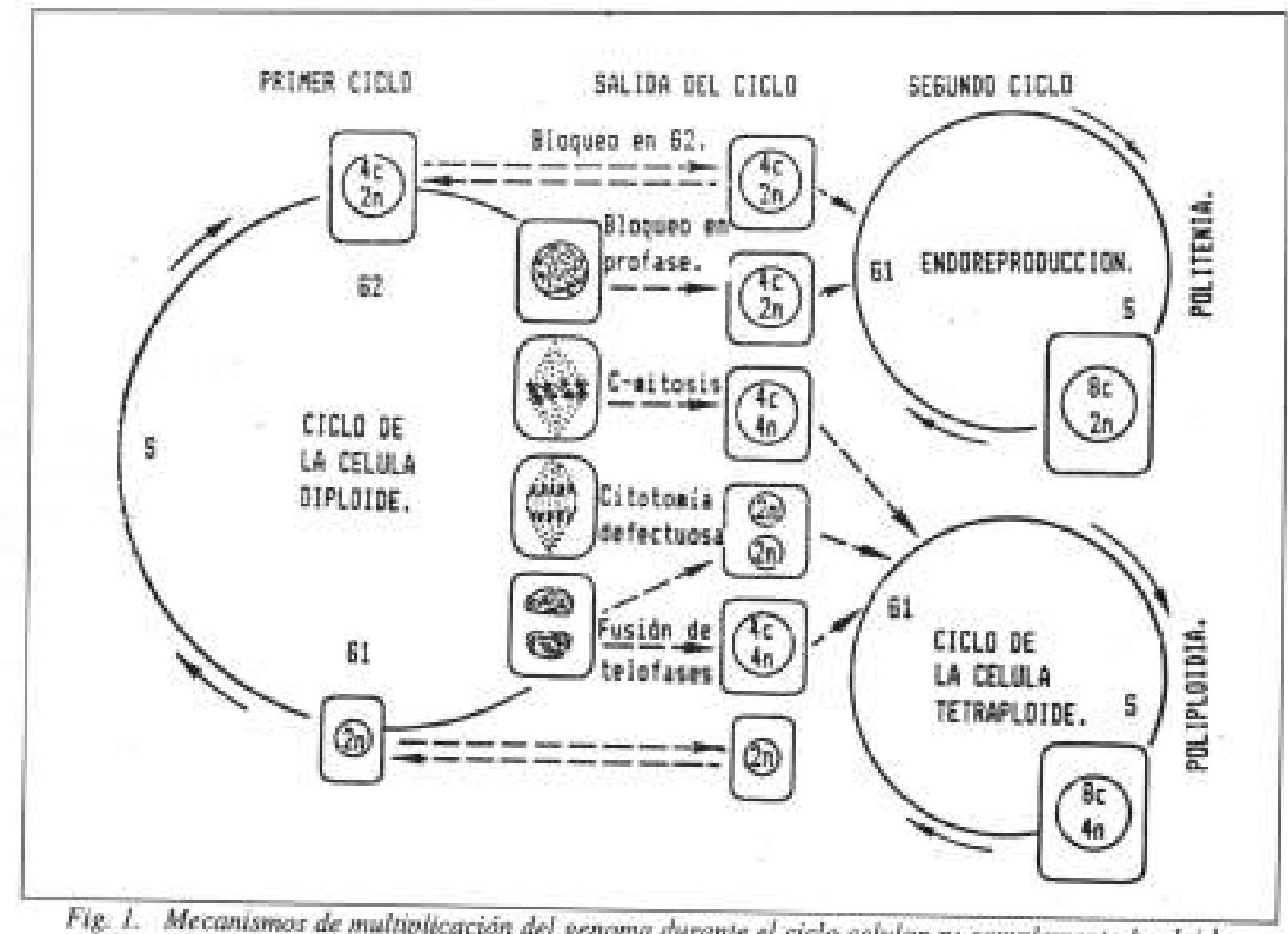

Fig. 1. Mecanismos de multaplicaciain del genoma durante el cicla celular n: complemento haploide de cromosomas; c; nivel haploide de ADN. (Tomado de Brodsky, Urivayeva, 1981.)

una célula con cromosomas (cromátides) duplicados pero que no se separan; en el siguiente ciclo, con diplocromosomas $y$, luego de varias endorreprodueciones, con cromosomas politénicos (fig. 1).

Estos reportes nos indican que tanto las mitosis normales como su transformación hacja ciclos mitóticos incompletos y hacia la poliploidización están condicionados por la realización del programa genético.

\section{MODIFICACION DEL CICLO CELUU AR}

La posibilidad de inhibir cualquier fase de la mitosis luego de la culminación de la anterior está condicionada por la regulación por fases del ciclo celular (Mezia, 1963. Epifánova, 1973). El bloqueo de la mitosis no impide la reproducción de los cromosomas; a su vez, la separación de los cromosomas y formación de los núcleos hijos no son pre-determinantes para la citotomía. El uso de inhibidores de la mitosis, que impiden la síntesis de las proteínas indispensables para el curso de una determinada fase, permite modelar el proceso de poliploidización. Las concepciones sobre las aproteínas de divisiono inicialmente se basaban en la permanencia de la celula en una u otra fase del ciclo después del bloqueo de fa sfintesis protéica en la fase anterior. La acción del inhibidor generalmente causaba poliploidía. Por ejemplo, la colchicina (Blakeslee \& Avery, 1937, cit. de Escobar, 1991: O'Mara,1939), el para-diclorobenceno (Meyer, 1945), el alfa-bromonaftaleno (Morrison, 1953) y la 8- hidroxiquinolina (Tjio \& Levan, 1950) inhiben la formación del huso acromático $y$, por lo tanto, la separación de los cromosomas duplicados; la 8azaguanina reorienta las células del meristemo radicular de Pisum hacia la endorreproducción (Nuti Ronchi et al. 1965). Asi mismo, la acción de la hidroxilamina sobre las células vegetales, además de otros efectos, bloquea ei paso de $G_{2}$ hacia la mitosis. En los ciclos siguientes se observan metafases con diplocromosomas (Lin \& Walden, 1974). Son especialmente interesantes los trabajos de Nagl (1970, 1978) y Nagl et al (1976) en los que se muestra claramente el bloqueo de las fases intermedias y finales de la mitosis con la acumulación correspondiente de células $4 \mathrm{C}$ (definiendo como $\mathrm{C}$ a la cantidad de material genético contenido en el complemento haploide) por acción de la actinomicina sobre cellulas diploides (2C) del meristemo radicular de cebolla.

Los experimentos con inhibición parcial de los procesos mitóticos y la poliploidización, como consecuencia de ello, posiblemente reproducen situaciones observables durante el desarrollo normal de los organismos. Sin embargo, el curso incompleto de la mitosis durante la ontogénesis no está condicionado por la acción de inhibidores, si no por el hecho de que no se completa el periodo preparatorio de la misma debido a la concurrencia de las funciones celulares (Brodsky \& Urivayeva, 1981),

El caraicter no-casual de la poliploidfa se infiere por la amplia difusión de células poliploides en plantas y animales, así como por la regulandad de su formación durante la ontogénesis. Sobre la determinación de la 
poliploidización nos habla su fuerte relación con periodos determinados del desarrollo. Esto nos demuestra la necesidad del fenómeno, así como las ya esclarecidas ventajas del genoma poliploide con respecto al diploide para el cumplimiento de algunas funciones histológicas o en la determinación de la vitalidad del tejido, Barlow (1978) sefial $\delta$ que la poliploidia puede ser una estrategia evolutiva. El éxito de esta estrategia no necesariamente estarí condicionado por alguna ventaja funcional inmediata de la célula poliploide, si no que puede estat determinado por la mayor capacidad de los órganos poliploides, respecto a los diploides, para resistir la influencia del medio ambiente (incluyendo daños físicos), como resultado de lo cual el organismo soporta mejor el proceso de selección.

\section{LA MITOSIS Y LA DIFERENCIACION}

Cada tipo celular esta formado por un conjunto integral de células predecesoras, intermedias, en proceso de maduración y formas finales en funcionamiento. La composición y actividad de estos conjuntos están determinados por la velocidad de la división celular, que garantiza el crecimiento o renovación de los tejidos, así como la permanencia (duración) de las formas finales, to que a su vez depende de la fisiología del tejido. Las células diferenciadas conservan su capacidad mitotica en los tejidos donde permanecen por periodos prolongados, donde no hay renovación celular o ésta se produce muy lentamente. Estos tejidos no presentan reservas troncales y la fuente principal del crecimiento de su masa es la reproducción de las células diferenciadas (Brodsky \& Urivayeva, 1981).

Una determinada diferenciación se caracteriza no sólo por una composición peculiar de sus proteínas, si no también por los límites de su producción. Está claro que además de las proteinas histoespecificas, que no son indispensables para su supervivencia, en las células diferenciadas se sintetizan componentes estructurales renovables y enzimas necesarias para el funcionamiento vital. En las células capaces de dividirse por mitosis se sintetizan proteinas especiales sin las cuáles éstas no podrian avanzar por el ciclo celular, replicar el ADN ni formar el aparato de la división. Durante el ciclo celular se sintetizan proteinas cromosómicas y se duplica la masa de las células. De forma que la masa total de proteínas producidas en el ciclo mitótico de las células diferenciadas es bastante grande. Se han observado variaciones interesantes del flujo de la mitosis en células en proceso de diferenciación. Prokofieva-Belgovskaya (1959, 1960) observ6́ la aparición de células binucleadas y mitosis con diplocromosomas en células de almacenamiento de almidón en tubérculos de papa. Se registró tanto la influencia de la función del tejido sobre el flujo de la mitosis como la inhibición de la formación de almidón cuando se estimulaban las mitosis. La no-selectividad de la inhibición es un argumento a favor de la competitividad entre la formación de almidón y la proliferación. No es improbable que el mecanismo de poliploidización generativa, de duplicación del genoma en las celulas de ta via sexual, sea el mismo. En este caso la posibilidad de aparición de poliploides por mutaciones es pequefla: para que el proceso se produzca se debería presentar una misma mutación en forma simultánea en las células sexuales masculinas y femeninas en un número bastante grande de organismos. La variación del nitmo de diferenciación y. como consecuencia, del flujo de la proliferación de las células sexuales puede producirse de manera simultánea en varios grupos de organismos si, por ejemplo, éstos se encuentran en condiciones de aislamiento en hábitats que presentan diferentes variaciones ambientales, como es el caso de las especies que se desarrollan en la Zona Andina ( National Research Council, 1989; Talledo, 1991; Jardin Betánico de Cordoba - Espanta, 1992). Como resultado del acortamiento del programa del ciclo celular se puede producir síntesis irregular del ADN, endorreproducción o poliploidía. La seleccí́n natural eliminará o no a la progenie cuyo genoma haya variado. Una via para verificar la posibilidad de estas variaciones es el estudio de poblaciones aisladas de una sola especie $y$ la determinación de la cantidad de ADN de sus genomas (Brodsky \& Urivayeva, 1981).

La importancia de la poliploidia somática consiste en la multiplicación de genes estructurales en aquellos tejidos donde por alguna causa no puede aumentar el número de células. La comparación de los parámetros del ciclo mitótico en 4 especies que se diferenciaban por el contenido de ADN en su genoma diploide en aproximadamente 20 veces permite establecer que los períodos $G_{1}$ y $\mathbf{S}$ aumentan en aquellas especies que presentan un genoma de mayor peso (Grosset \& Odartchenko, 1975 a, b). Como veremos mas adelante, en celulas vegetales se ha encontrado correlación entre el peso del genoma y la duración del ciclo.

\section{PECULIARIDADES DE LAS CELULAS VEGETALES}

El aumento de la cantidad de ADN en las células vegetales puede estar condicionado tanto por poliploidia (aumento del número de cromosomas durante el desarrollo de algunas células), como por politenia (multiplicación del número de crotnonemas en cromosomas que no se dividen). Los mecanismos de formación de celulas poliploides y la importancia funcional del proceso no difieren en principio en vegetales $y$ animales.

Sin embargo, las células vegetales presentan algunas peculiaridades. Una de las diferencias principalen de las cellulas vegetales con respecto a las animales es la gran variabilidad del peso del genoma diploide. En las plantas angiospermas los valores de $2 \mathrm{C}$ para el $\mathrm{ADN}$ varian aproximadamente 500 veces: desde $0.5 \mathrm{pg}$ (picogramos) 
an Arabidopsis thaliana hasta $255 \mathrm{pg}$ en Fritillaria assirica (Ivanov, 1978), Las células de muchas plantas contienen mucho más ADN que las de los mamiferos, aunque no está clara la importancia de este hecho (Prokofieva-Belgovskaya, 1986), Se ha establecido que el volumen del núcleo puede duplicarse y multiplicarse manteniendo un número constante de cromosomas: por ejemplo durante el crecimiento de la célula diploide y en diferentes fases de secreción (Jesin, 1967), En una serie de trabajos se ban reportado observaciones morfologicas de macronúcleos en células vegetales. Estos resultados son más numerosos que las determinaciones citofotométricas

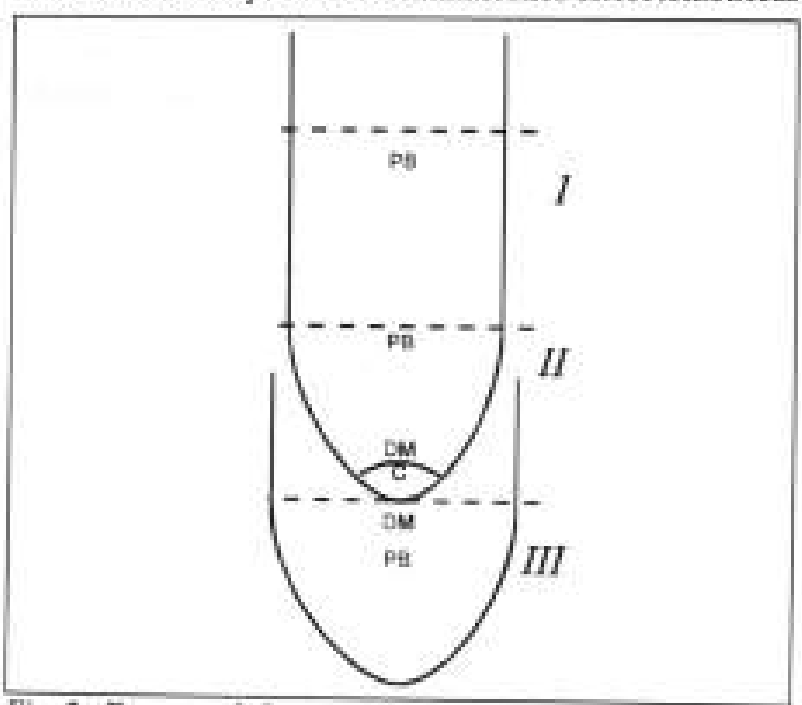

Fig. 2. Escquema de lar zonas de la raíz, indicando las peculiaridades de la prollferaciän celular: I: Zona de alorgamiento. II: Meristemo, III: Cojia DM. Divisianer mitóticas, PB: Mitosis poliploidizantes y bloqueo en la fase G2 del ciclo. C: Centro en reposa (Tomado de Tschermack-Woess, 1956; Manov, 1974: Barlow, 1977b; cit, de Brodsky, Urivayene, 1981).

del contenido de ADN (Nagl, 1978), Sin embargo, la poca confiabilidad del criterio wolumétrico para evaluar el nivel de ploidía es evidente, aunque sólo sea por la diferente densidad optica de los núcleos, condicionada por un mayor grado de condensación. El criterio del tamaño puede ser utilizado con éxito siempre y cuando se mantenga un control citofotométrico o se utilicen criterios adicionales de identificación (Pijnacker ef al. 1989).

Por otro lado, existen diferencias más especificas. Veamos algunos cjemplos:

$1^{\circ}$ En células radiculares, Ivanov (1974) scâlala una serie de peculiaridades importantes del crecimiento y desarrollo de las células de la raíz. Como se sabe, en el ápice radicular se observan células de un centro en reposo, del meristemo y de la zoaa de alargamiento. En el centro en reposo se localizan las celulas troncales de los tejidos de la raíz. El meristemo es la zona de multiplicación celular: aquí y en la cofia, en sus capas próximas a la raf́, se observan las mitosis (Foard, 1970) (Fig. 2), El aúmero de capas celulares delmeristemo depende del grosor de la raíz. Los meristemos de raices muy finas contienen alrededor de 10 capas, mientras que en raf́ces gruesas es posible encontrar varios cientos de ellas.

Con respecto a la duración del ciclo celular, ésta depende del peso del genoma: cuanto mayor es la cantidad de ADN tanto mayor es la duración del ciclo y el período de síntesis. Esta relación, señalada por primera vez por Van't Hoff y Sparrow en 1963, ha sido estudiada por muchos autores. El espectro de resultados para las diferentes especies es grande, pero la correlación entre el contenido de $\mathrm{ADN}$ en el genoma diploide y la duración del ciclo mitótico es indudable (Ivanov, 1978) (Fig. 3).

Se puede relacionar la duración del ciclo con la ecología de la planta. La cantidad de ADN en el genoma diploide y el tiempo de reproducción de las células

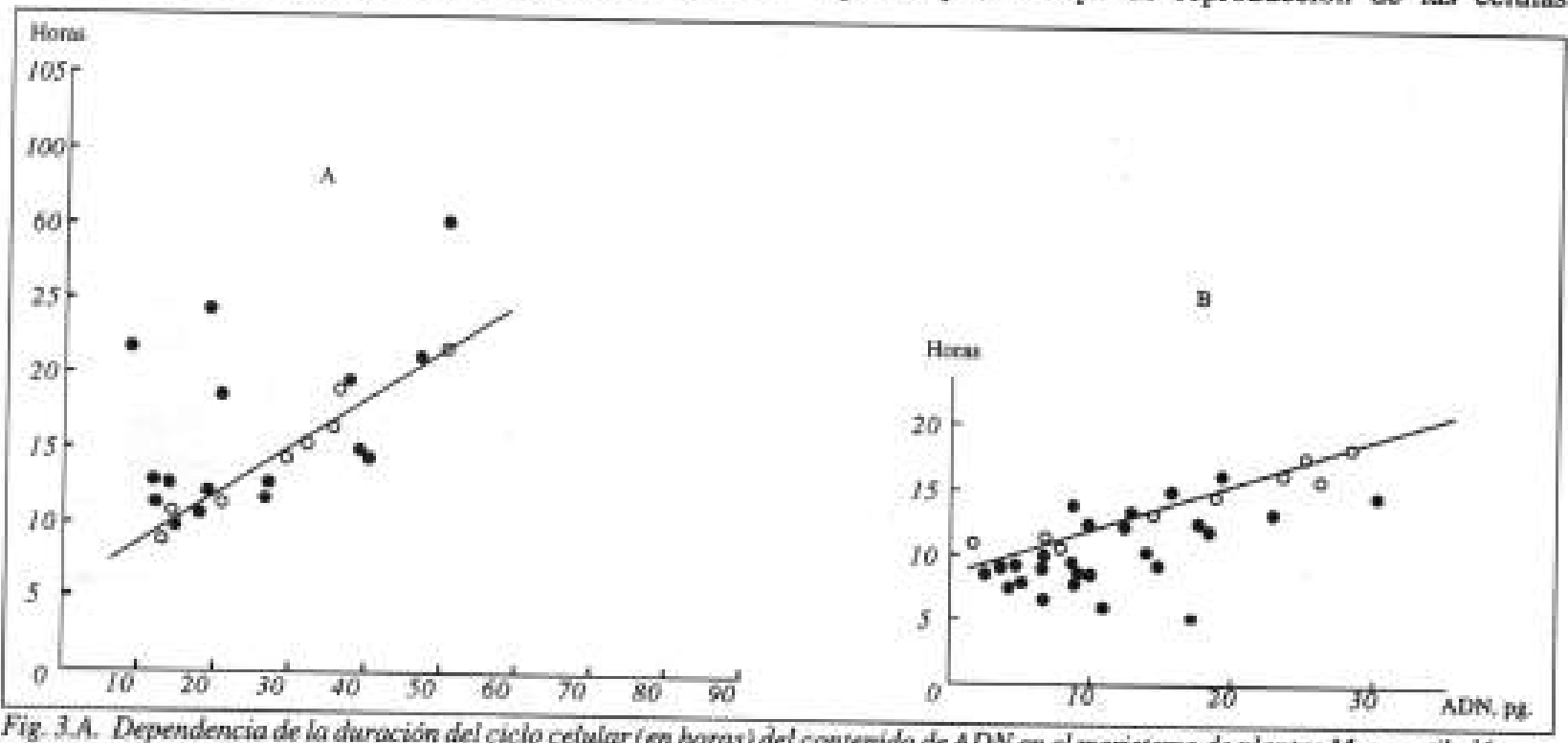

Fig. 3.A. Dependencia de la duración del ciclo ceíular (en horas) del contenido de ADN en el meristemo de plantas Monoconiledóneas. Los puntas y circulos representan diferentes especies vegetales, (Tvanov, 1978). B. Dependencia de la duración del ciclo celalar (en vegetales. (Kuntov, 1978). 
frecuentemente forman una curva en crecimiento cuando comparamos las plantas efimeras. las anuales $y$ las pereanes (Bennett, 1972). Las formas diploides y poliploides de una misma especie por lo general presentan ciclos similares.

La diferenciación cehular empieza en el meristemo. El nû́mers de mitosis disminuye conforme nos aproximamos a la zona de alargamiento. La ctapa de alargamiento es especifica para el desarrollo de las células vegetales y está condicionada por la hidratación del citoplasma y la acumulación en el mismo de una serie de sustancias, incluyendo proteinas. Esto permite considerar que el crecimiento de las celulas consiste en su alargamiento (ecrecimiento por alargamientow). En el proceso de ulargamiento aparecen las principales diferencias de las celulas de los tejidos. El alargamiento no siempre bloquea la mitosis y la sintesis de ADN se produce en muchas células diferenciadas. Por lo general, en las células de la zona de alargamiento no se producen mitosis luego de la replicación del ADN; las mitosis tampoco son frecuentes en las células distales del meristemo.

Como resultado de la sintesis de ADN sin mitosis posterior, en el meristemo y en la zona de alargamiento se acumulan celulas con una cantidad de $\mathrm{ADN}$ duplicada $y$ hasta cuadruplicuda (Van Parijs \& Vandendriessche, 1966: Brunori, 1971). Así mismo, el procesamiento de las raíces con colchicina, que inhibe la mitosis, noevita la acumulación de ADN y el crecimiento de las celulas (Barlow, 1977). En los tejidos radiculares también se ban soservado mitosis poliploides (Sinnot, 1960; Matthysse \& Torrey, 1967; Libbenga \& Torrey, 1973; Hervas, 1975). Cuanto más alejadas están las celulas del extremo de las rafces, es decir, cuanto más han avanzadoen su diferenciación, tanto mayor es la cantidad de mitosis tetra-y octaploides. Por ejemplo, cerca al extremo de la raíz de Pisum satrivam L. el 75 \% de las mitosis es diploide; a una distancia de $5 \mathrm{~mm}$. del extremo de la ráx esta cantidad será sólo del $5 \%$ y el resto será poliploide (Libbenga \& Torrey, 1973).

Como bemos visto, luego de la reproducción celular, en las capas apicales del meristemo se produce endareprodacción y en las capas distales, mitosis poliploidizantes; éstas continuan en la zona de alargamiento.

2 En células foliares. La endoreproducción es también característica para los tejidos foliares, especialmente para las hojas de plantas suculentas (D'Amato, 1977).

$3^{\circ}$ En órganos del desarrollo embrional. Las variaciones cuantitativas del ADN ea los órganos del desarrollo embrional de las plantas son más significativas que en los tejidos definitivos. Una gran cantidad de ADN se acumula en las cellulas del suspensor (embrióforo), donde se observan cromosomas politénicos. (El suspensor de las plantas angiospermas es producto del blastómero basal; del otro blastómero se forma el embrión. Las divisiones del blastómero basal dan lugar a una hilera de células: el suspensor, que empuja al embrión a la parte ceatral del saco embrional. En este momento en el saco embrional se forma el endosperma, también a través de divisiones celulares). Tanto en el suspensor como en el endosperma se pueden encontrat células gigantes, las de mayoe tamaño se ubican en la parte basal del suspensor. Generalmente, las especies que presentan suspensor poco desarrollado presentan células gigantes en el endosperma (D' Amato, 1977: Nagl, 1978). El mayor número de trabajos de este tipo ha sido desarrollado en Phaseolus, cuyos embrioforos están formados por 100 - 150 células, la mayoría de las cuales presenta entre $4 \mathrm{c}$ y $64 \mathrm{c}$ (Brodsky \& Urivayeva, 1981).

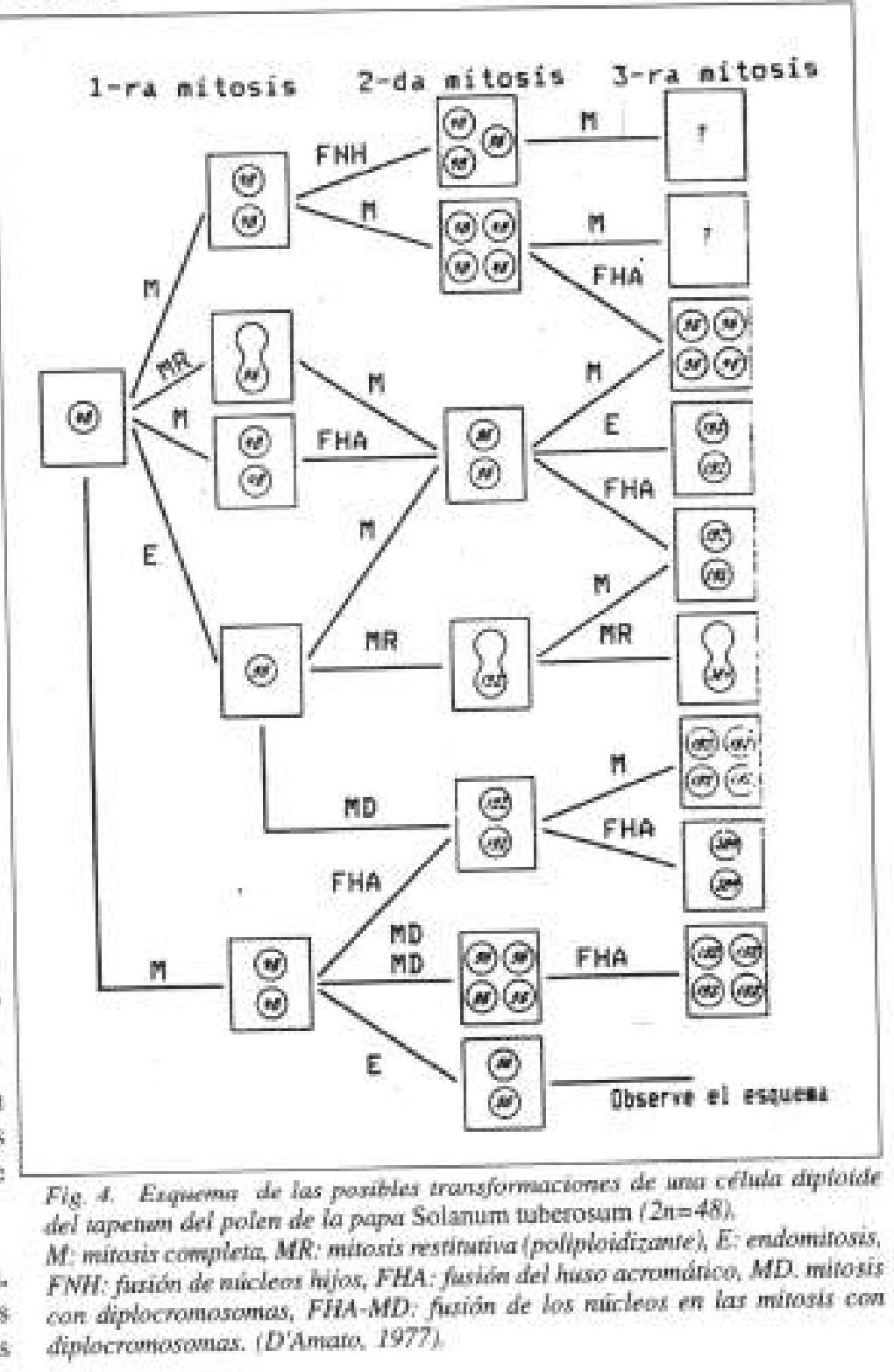


En las plantas angiospermas las células del endosperma son originalmente triploides (3x). En especies como Bonassius flabellifer, la palma azucarera, además de células $3 \mathrm{x}$, se han encontrado células $6 \mathrm{x}, 12 \mathrm{x}$, $24 x, 48 x$ y $96 x$ (Stephen, 1974), La poliploidización en el endosperma puede ser condicionada por mitosis incompletas, lo mas frecuente son bloqueos de metafases, cuando se destruye la membrana nuclear, se espiralizan los cromosomas, pero el huso acromático no se forma. Otra vía de poliploidización característica del endosperma es el bloqueo de la mitosis durante la anafase. Stephen (1973) observó tambiés la potitenización en el endospermo de maíz

$4^{\circ}$ En el tapetum (tapete) del polen. Durante el desarrollo del tapetum del polen en papa se puede producir una serie de transformaciones del núcleo diploide (D'Amato, 1977). En la Fig, 4 se observa que las células pasan por 3 mitosis; una parte de ellas mantiene un sólo núcleo, aumentando significativamente su genoma como resultado de mitosis poliploidizantes; otra parte, la mayoría de las células, pasa por una mitosis acitocinética, transformandose en binucleadas y continúan dividiéndose por bimitosis (mitosis en células binucleadas). En algunas de estas células los complementos de la progenie se fusionan (por pares), dando lugar a células binucleadas con un mayor nivel de ploidia. Por último, en las bimitosis de un tercer grupo de células los núcleos se dividen hasta el final y se forman células tetranucleadas. La bimitosis puede repetirse, dando lugar a células bi- y tetranucleadas en un mayor aivel de ploidía. Es poco frecuente que se fusione parte de los núcleos-hijos ya formados, lo que da lugar a cellulas trinucleadas con núcleos en diferentes niveles de ploidia.

\section{MATERLALES Y METODOS}

\section{CONDICIONES AMBIENTALES}

Para la determinación de los Indices de Fases (IF). Indice Mitótico (IM) y duración del ciclo celular en vegetales es conveniente registrar las condiciones de laboratorio (tales como temperatura, humedad relativa y presión atmosférica) durante el experimento.

\section{MATERIAL BIOLOGICO}

El material biológico comprende meristemos radiculares de semillas, granos o tuberculos, obtenidos a partir del extremo fistal de rafoes primarias o secundarias de color blanco o crema, de aspecto brillante y consistencia fragil, con una longitud aproximada de $1.0-1.5 \mathrm{~cm}$.

\section{CONDUCCION DEL EXPERIMENTO GERMINACION DE LAS MUESTRAS}

Las muestras (semillas, granos o esquejes de tubérculos) deben germinar en cámaras húmedas confeccionadas en placas Petri de $15 \times 100 \mathrm{~mm}$ Previamente el interior de éstas debe ser desinfectado con alcobol al $75 \%$, cubriéndose luego con papel filtro humedecido en agua.

Nota: En tubérculos los esquejes se separan de su base mediante movimientos rotatorios, descartaindose aquellos esquejes de consistencia blanda y/o que presenten lesiones.

\section{DETERMINACION DEL INDICE MITOTICO}

\section{FIJACION}

Los meristemos radiculares se colocan a diferentes horas del día en solución fresca del fijador Camoy (Etanol absoluto + Acido acético glacial en una proporción de 3:1, respectivamente) donde permanecen por espacio de $4: 006$ más boras (hasta 6 meses como máximo) a $4^{\circ} \mathrm{C}$

\section{COLORACION}

Para la coloración de las muestras se usa orceina acética clorhídrica de acuerdo al método de Tjo \& Levan (1954) modificado por Talledo y Escobar (1993).

Las raices se transfieren a una solución $\mathrm{A}$ del colorante (orcefna acética al $4,4 \%+\mathrm{HCl} 1 \mathrm{~N}, 9: 1$ vol.), calentándose por pocos segundos hasta obtener el desprendimiento de vapores y alcanzar una temperatura tal que sea soportada en el dorso de la mano, evitándose la ebullición y el calentamiento excesivo. Luego se deja enfriar y se repite el paso anterior tres veces. Después de ello se deja enfriar por completo.

\section{PREPARACION DE LA MUESTRA PARA EL SQUASH}

Las porciones radiculares asf teâlidas se colocan sobre un portaobjetos, cortándose $1 \mathrm{~mm}$ del meristemo con una hoja de bisturi; el resto se descarta, eliminándose el excedente de solución A. Finalmente se agrega 1 o 2 gotas de solución B (orceína acética al $4.4 \%+\mathrm{HCl}$ al $45 \%$, $1: 1$ vol.), dejando las muestras en la misma durante 10 minutos, para luego realizar el squash con un cubreobjetos.

\section{PRENSADO O SQUASH}

Luego de colocar el cubreobjetos se golpea firme y fuertemente la muestra con una varilla de goma. Este golpe va a causar la separación de las celulas cuyas uniones han sido destruidas durante el tratamiento con scido clorhídrico, incluído en la coloración. Seguidamente, con la misma varilla, se golpea repetidamente la muestra a través del cubreobjetos, en espiral, del centro hacia la periferie, para que los movimientos de *subida - bajada* de la laminilla motivados por el golpeteo permitan la disociación del tejido meristemático.

A coatinuación se realiza el aplastamiento presionando fuertemente la límina con el dedo pulgar, evitando 


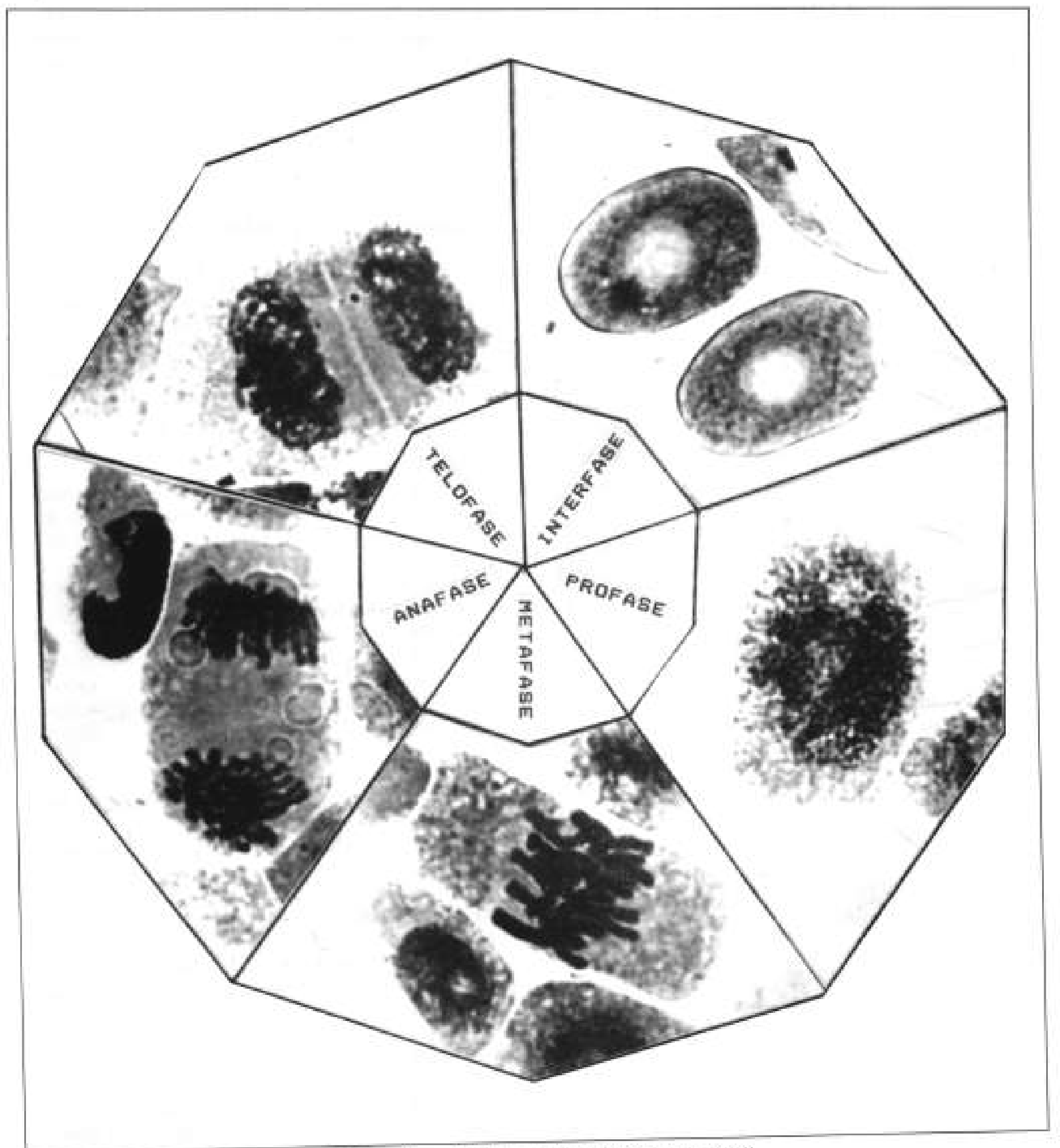

FOTO I, Fases del ciclo celular en Lepidium meyenii,

Cuadro A: Evaluación de los indices de fases e findices mitóticas.

\begin{tabular}{|c|c|c|c|c|c|c|c|}
\hline $\begin{array}{c}\text { Hora } \mathbf{T}\left(\mathbf{C}^{\circ}\right) \\
\text { IF }(\%)\end{array}$ & $\begin{array}{l}\text { Células } \\
\text { contadas }\end{array}$ & Interf. & Prof. & Metaf. & Anaf. & Telof. & $\begin{array}{l}\text { IM } \\
(\mathbb{E})\end{array}$ \\
\hline
\end{tabular}


cualquier movimiento del cubreobjetos, Ex recomendable que la lámina se encuentre sobre una superficie antideslizante. Finalmente, se envuelve la lámina en papel filtro $y$, luego de colocarla nuevamente sobre la mesa de trabajo, se ejerce presión sobre la misma, esta vez con la parte inferior de la palma de la mano.

Nota: Para la obtención de un buen squash es indispensable que en todos los pasos mencionados la presión sea perpendicular a la lámina; lo que permite la distribución de las celulas en una sola capa, facilitando la diferenciación de las diferentes fases del ciclo celular.

OBSERVACION AL MICROSCOPIO: CONTAJE DE FASES - DETERMINACION DE LOS INDICES DE FASES E INDICES MITOTICOS PARCLALES

Las muestras procesadas de cada hora son observadas al microscopio con el propósito de determinar el lndice de fases ( $(T)$ mediante el contaje de las difereates fases del ciclo selular (interfase, profase, metafase, anafase y telofase) en aproximadamente 1,000 células, registradas y expresadas en porcentajes (Foto 1). Finalmente la sumatoria de células en división (profase, metafase, anafase y telofase) respecto al total de células expresada en porcentajes constituye el Indice Mitótico ( $\left.\mathrm{M}^{\mathrm{M}}\right)$.

Fórmulas parciales (observación por c/hora):

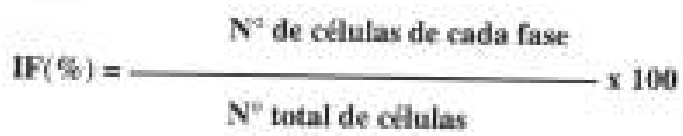

$$
\mathrm{IM}(\%)=\mathrm{IFP}+\mathrm{IFm}+\mathrm{IFu}+\mathrm{IFt}
$$

Donde: $\mathrm{IF}=$ Indice de fases, $\mathrm{IM}=$ Indice mitótico, $\mathrm{p}=$ profase, $\mathrm{m}=$ metafase, $\mathrm{a}=$ anafase $\mathrm{y} \mathrm{t}=$ telofase.
Para facilitar el análisis de los resultados se propone un cuadro de registro de la evaluación de los indices de fases $e$ indices mitóticos (Cuadro A). Este cuadro incluye la hora (en la cual se produjo la fijación de la muestra), el número de células contadas (no menos de 1,000 hora), las diferentes fases expresadas en porcentajes y finalmente la determinación de los indices mitóticos parciales y el Indice Mitótico total, expresados también en porcentajes:

\section{DETERMINACION DE LOS IF E IM TOTALES Y DE LA DURACION DEL CICLO CELUL AR.}

Los IF(\%) totales se obtienen de la división de la sumatoria de los porcentajes de cada fase de la mitosis, obtenidos para cada hora, entre el número total de horas.

Con estos porcentajes se determina el IM total mediante la sumatoria de los indices de fases en división (profase, metafase, anafase y telofase).

Fórmulas totales:

$$
\begin{aligned}
& \mathrm{IF}(\xi)=\frac{\mathrm{IF} \% \text { parciales de cada fase }}{\mathrm{N}^{*} \text { de horas }} \\
& \mathrm{M}(\%)=\mathrm{IFp}+\mathrm{IFm}+\mathrm{IFu}+\mathrm{IFt} \text { (IF totales) }
\end{aligned}
$$

La proporción de células en las fases de la mitosis respectoal total de celulas de la muestra (el índice mitótico -IM) va a reflejar directamente la duración relativa de dichas fases, asi como de la propia mitosis. En un sistema asincrónico, como son los cromosomas en la célula en división, esta información es insuficiente para establecer en términos absolutos la duración de cada fase individualmente. Para ello es preciso, además, conocer cual es la duración del ciclo celular.

Para determinar la duración del ciclo mitótico es necesario evaluar la duración en horas para cada fase en un período de tiempo suficiente, durante el cual se observe claramente el inicio y el final de las mitosis en porcentajes significativos de las células de la muestra.

Cuadno B: Determinación de los IF e IM torales y de la duración del cinlo celalar

\begin{tabular}{|l|l|l|}
\hline Estado Total Interf. Prof. Metaf. Anaf. Telof. \\
\hline Frecuencia \\
\hline FF (\%) \\
\hline IM (\%) \\
\hline $\begin{array}{l}\text { Duración Hrs } \\
\text { asumiendo un } \\
\text { valor medio } \\
\text { para un ciclo } \\
\text { completo }=\text { Hrs. }\end{array}$ \\
\hline
\end{tabular}




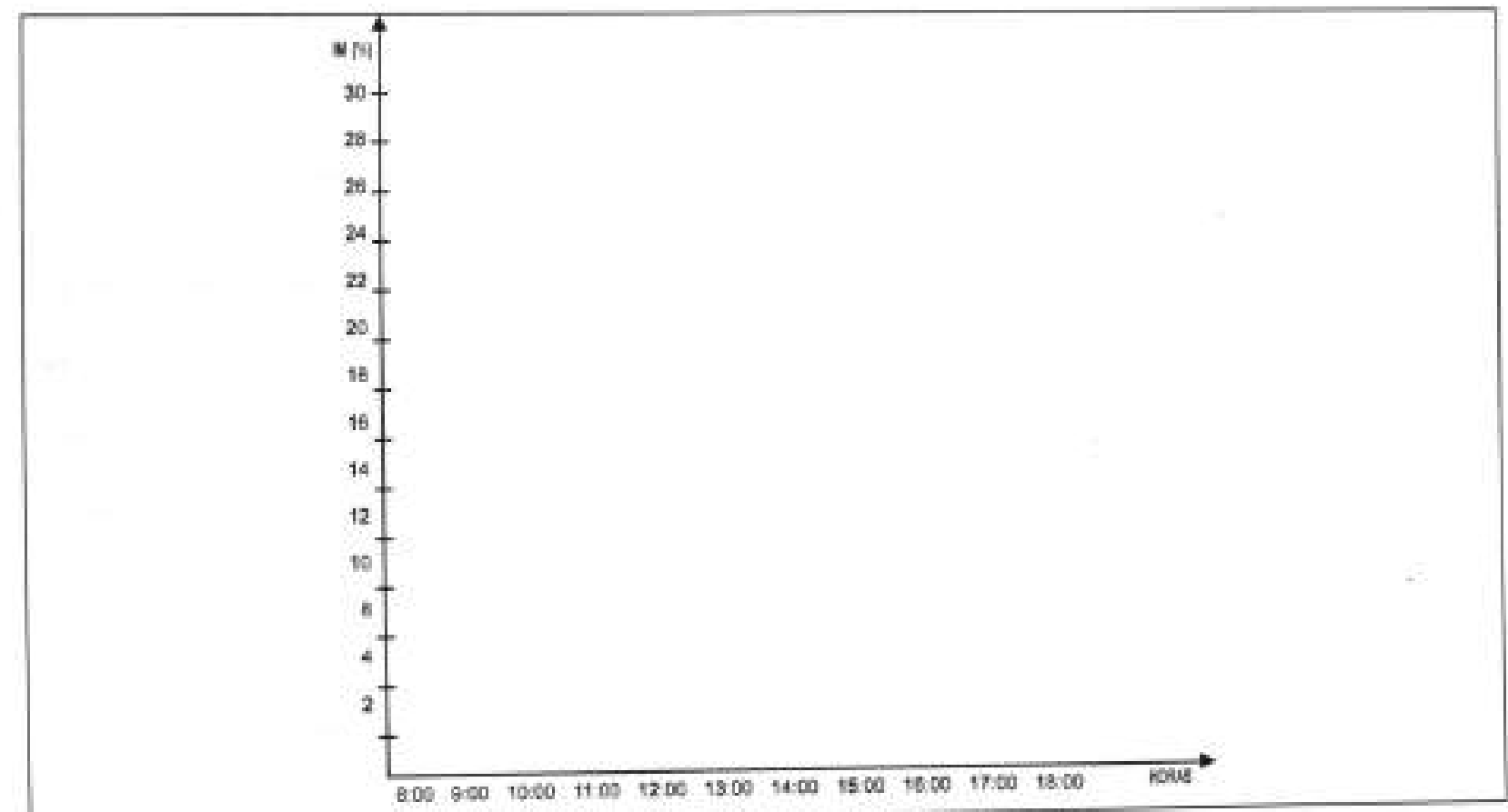

Girafice C: Secuencia del Ciclo Celular

calculando la duración total del ciclo mediante la sumatoria de los periodos ocupados por la profase, metafase, anafase $y$ telofase.

Para ello se precisa determinar los IF totales. Fórmula duración $\mathrm{CC}$ :

\section{$\mathrm{CC}=$ Valores en horas de las fases en división y en interfase. \\ Donde $\mathrm{CC}=$ ciclo celular.}

Un valor elevado para el IM no nos indica que la división se produce rápidamente, si no más bien que ta mitosis ocupa una gran parte del tiempo total del ciclo celular (Dyer, 1979). Este método permite determinar los valores promedio, aunque debemos tener en cuenta que se pueden presentar variaciones incluso entre las celulas de un mismo meristemo.
Se sugiere un cuadro de registros (Cuadro B) que incluye para todas las fases del ciclo celular: la frecuencia del nümero de células, el índice de fases e índice mitótico en porcentajes y la duración en horas asumiendo un valor medio para un ciclo completo (en base a la curva de las mitosis obtenida en el Gráfico C).

Finalmente, para ilustrar los resultados con claridad, se propone un gráfico cuyas coordenadas representan la secuencia del ciclo celular e incluyen el total de horas registradas y los indices mitóticos en porcentajes (Gráfico C).

\section{RESULTADOS}

A manera de ejemplo se presentan los resultados de tres investigaciones en las que se determina el Indice mitótico y se estudia el CicloCelularen los géneros: Zea Phaseolus y Ullucus.

Cnadro I. Evahación de los Indices de Fases e Indices Mitóticos Parciales en 4 Especies del Género Phaseolus.

\begin{tabular}{|rcrrrrrr|}
\hline Hora & $\begin{array}{c}\text { Células } \\
\text { contadas }\end{array}$ & $\begin{array}{c}\text { Interf. } \\
\text { IF(\%) }\end{array}$ & $\begin{array}{c}\text { Prof. } \\
\text { IF(\%) }\end{array}$ & $\begin{array}{r}\text { Metaf. } \\
\text { IF(\%) }\end{array}$ & $\begin{array}{r}\text { Anaf. } \\
\text { IF(\%) }\end{array}$ & $\begin{array}{r}\text { Telof. } \\
\text { IF(\%) }\end{array}$ & $\begin{array}{r}\text { IM } \\
(\%)\end{array}$ \\
\hline $8: 00$ & 1200 & 100.00 & 0.00 & 0.00 & 0.00 & 0.00 & 0.00 \\
$9: 00$ & 1200 & 100.00 & 0.00 & 0.00 & 0.00 & 0.00 & 0.00 \\
$10: 00$ & 1200 & 72.77 & 14.99 & 3.05 & 3.22 & 5.97 & 27.23 \\
$11: 00$ & 1200 & 81.47 & 7.66 & 2.57 & 2.16 & 6.14 & 18.53 \\
$12: 00$ & 1200 & 88.95 & 8.60 & 1.10 & 0.87 & 0.48 & 11.05 \\
$13: 00$ & 1200 & 91.97 & 5.82 & 0.62 & 0.96 & 0.63 & 8.03 \\
$14: 00$ & 1200 & 93.24 & 4.92 & 0.26 & 0.92 & 0.66 & 6.76 \\
$15: 00$ & 1200 & 98.63 & 0.25 & 0.43 & 0.26 & 0.43 & 1.37 \\
$16: 00$ & 1200 & 96.95 & 0.00 & 1.38 & 0.32 & 1.35 & 3.05 \\
$17: 00$ & 1200 & 98.45 & 0.30 & 0.62 & 0.00 & 0.63 & 1.08 \\
$18: 00$ & 1200 & 96.94 & 0.35 & 1.28 & 0.35 & 1.08 & 3.06 \\
\hline
\end{tabular}




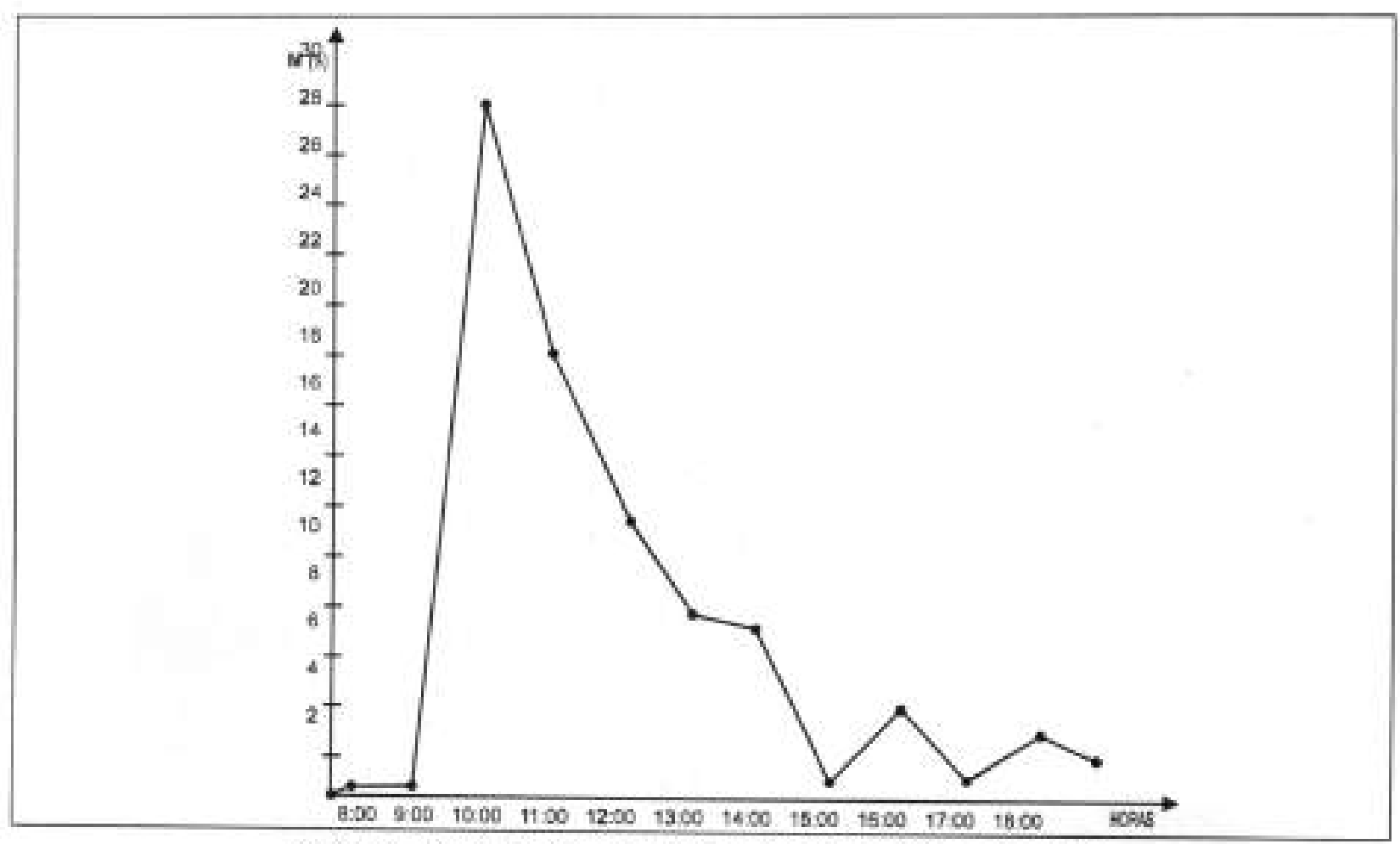

Graffico 1. Secuencia del Ciclo Celinlar en 4 especies del Género Phaseolus.

Cunatro 2. Deteminación de los IF e IM tonales y de la duración del ciclo celular en 4 especies del geinero Phaseolus.

\begin{tabular}{|c|c|c|c|c|c|c|}
\hline Estado & Total & Interf. & Prof. & Metaf. & Anaf. & Telof. \\
\hline Frecuencia & 13,200 & 12,232 & 515 & 136 & 109 & 208 \\
\hline IF $(\%)$ & 100 & 92.66 & 3.90 & 1.03 & 0.83 & 1.58 \\
\hline $\mathrm{IM}(\%)$ & 7.34 & \multicolumn{5}{|c|}{$(3.90+1.03+0.83+1.58)$} \\
\hline $\begin{array}{l}\text { Duración Hrs } \\
\text { asumiendo un } \\
\text { valor medio }\end{array}$ & 10.00 & $(9.27)$ & $(0.39)$ & $(0.10)$ & $(0.08)$ & $(0.16)$ \\
\hline $\begin{array}{l}\text { para un ciclo } \\
\text { completo = } \\
10: 00 \mathrm{Hrs}\end{array}$ & $10: 00$ & $9: 16$ & $0: 23^{\prime \prime}$ & $0: 06$ & $0: 05$ & $0=10^{\prime}$ \\
\hline
\end{tabular}

\section{DURACIONDEL CICLOCELULAR ENCELULAS DE MERISTEMO RADICULAR DE MAIZ. Autor: Verma (1979).}

La duración del ciclo celular en celulas de meristemo radicular de maíz es de 11:30 horas, la mayor parte de las cuales es ocupada por la interfase (10-00 - 10:50 horas). mientras que la mitosis tiene una duración de 1:34 horas, La duración de la interfase y mitosis en muestras de una serie poliploide $(2 n=2 x, 3 x, 4 x)$ de la línea autofecundante de maíz W23 se mantuvo sin variaciones $(10: 00,1: 30 ; 10: 40$, 1:10: 10:20, 1:30 horas, respectivamente). La duración del ciclo celular en líneas de diferentes genotipos presentó variaciones: 9:90 horas para la línea Seneca $60,10: 60$ boras para KYS y el control, de 9.00 a 11:30 horas para la linea W23. La duración de la mitosis fué de 1:10, 1:12, 0:81 y 1:29 horas, respectivamente.
II. CARACTERIZACION CARIOTIPICA EN ESPECIES DEL GENERO PHASEOLUS.

Autores: Talledo, Eseobar (1995). (Investigación financiada parcialmente por CONCYTEC, 93-94).

Muestras procedentes del Departamento de Ica (PERU). fueron proporcionadas por el Banco de Sernillas del Instituto Nacional de Investigaciones para la Agricultura (INLA) filial de ICA. La temperatura durante el muestreo fue de $21^{\circ} \mathrm{C}$, la humedad relativa, $81 \%$.

En base a la evaluación del número de células en división y al número de células hijas producidas a partir de las primeras en un periodo de tiempo de 10 horas en 4 especies del género Phaseolus: Ph. acutifolius Gray. "Frijol ayocoten, $P h$ aureus L. aFrijol chinos, $P h$. caccineus L. «Frijol tepary* y Ph. lunatus L. *Pallar», fué 


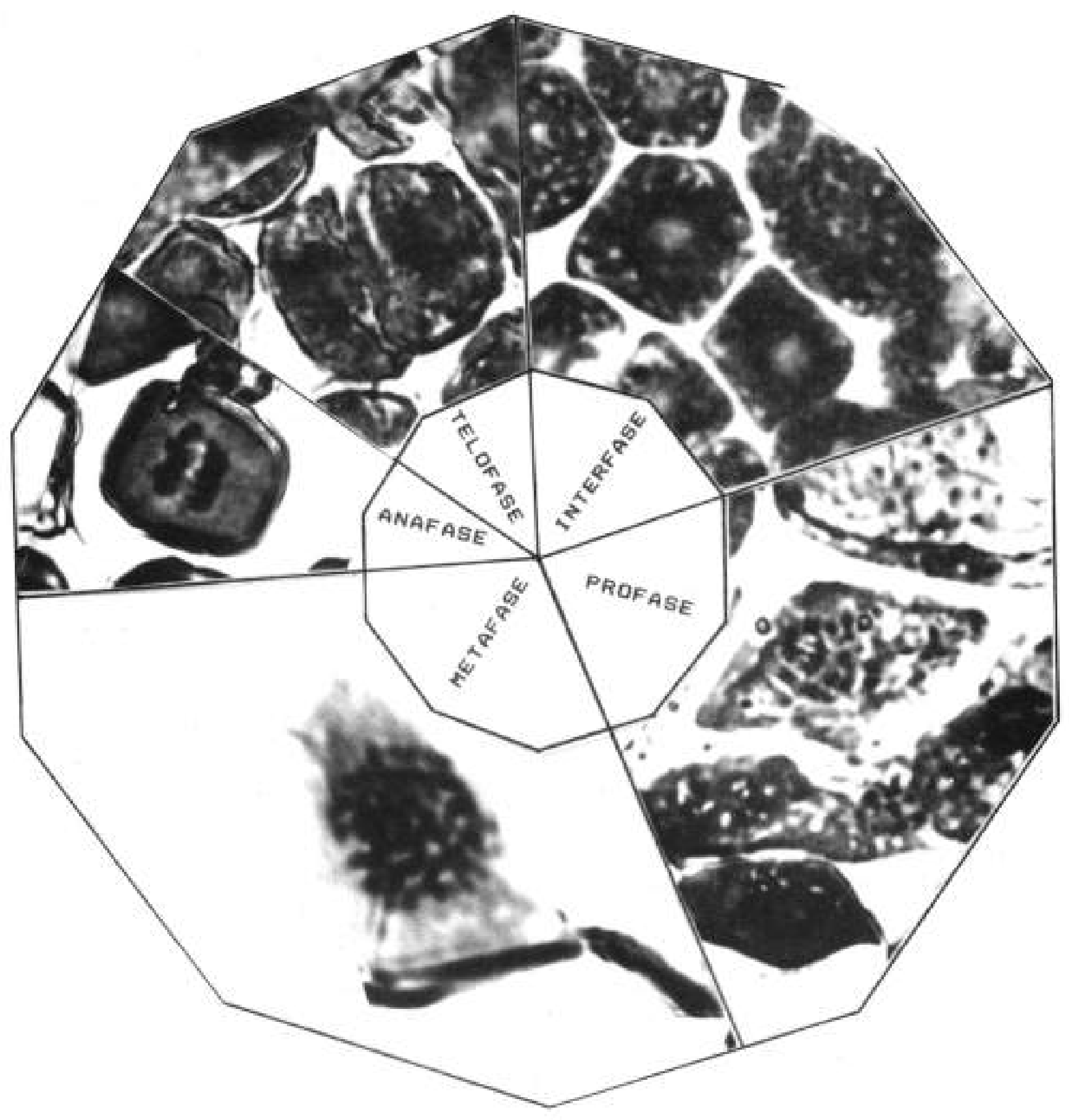

FOTo 2. El cicia celular en Ullucus 
Cuadino 3. Evaluación de los Indices de Fares e indices, Mitóticos Parciales en 10 accesiones de Ollucus.

\begin{tabular}{|rrrrrrrr|}
\hline Hora & $\begin{array}{c}\text { Celulas } \\
\text { contadas }\end{array}$ & $\begin{array}{l}\text { Interf. } \\
\text { IF }(\%)\end{array}$ & $\begin{array}{c}\text { Prof. } \\
\text { IF }(\%)\end{array}$ & $\begin{array}{c}\text { Metaf. } \\
\text { IF }(\%)\end{array}$ & $\begin{array}{r}\text { Anaf, } \\
\text { IF(\%) }\end{array}$ & $\begin{array}{r}\text { Telof. } \\
\text { IF(\%) }\end{array}$ & $\begin{array}{r}\text { IM } \\
(\%)\end{array}$ \\
\hline $9: 40$ & 1300 & 96.00 & 0.00 & 0.85 & 0.38 & 2.77 & 4.00 \\
$10: 00$ & 1300 & 96.77 & 0.85 & 1.38 & 0.69 & 0.31 & 3.23 \\
$10: 30$ & 600 & 92.77 & 1.67 & 2.67 & 3.00 & 0.00 & 7.24 \\
$11: 00$ & 600 & 96.67 & 0.50 & 0.50 & 0.17 & 2.17 & 3.34 \\
$11: 30$ & 900 & 96.22 & 0.00 & 0.00 & 0.00 & 3.78 & 3.78 \\
$12: 00$ & 350 & 88.57 & 0.00 & 0.29 & 0.29 & 10.85 & 11.43 \\
$13: 00$ & 1600 & 00.00 & 99.06 & 0.57 & 0.19 & 0.19 & 100.00 \\
$14: 00$ & 290 & 94.14 & 4.97 & 0.34 & 0.00 & 0.55 & 5.86 \\
$15: 00$ & 600 & 96.08 & 0.00 & 0.00 & 0.00 & 3.92 & 3.92 \\
$16: 00$ & 350 & 88.61 & 0.00 & 0.25 & 0.25 & 10.90 & 11.40 \\
\hline
\end{tabular}

Ciadro 4. Deienninación de les IF e IM vorales y de la duración del ciclo celular en 10 accesinnes de Ullucus.

\begin{tabular}{|lcccccc|}
\hline Estado & Total & Interf. & Prof. & Metaf. & Anaf. & Telof. \\
\hline Frecuencia & 7,890 & 6,673 & 844 & 54 & 40 & 279 \\
\hline IF $(\%)$ & 100 & 84.58 & 10.70 & 0.68 & 0.50 & 3.54 \\
\hline IM (\%) & 15.42 & & $(10.70+0.68+0.50+3.54)$ & \\
\hline $\begin{array}{l}\text { Duración Hrs } \\
\text { asumiendo un } \\
\text { valor medio } \\
\text { para un ciclo } \\
\text { completo } \\
6: 20 \text { Hrs }\end{array}$ & 6.20 & $(5.25)$ & $(0.66)$ & $(0.04)$ & $(0.03)$ & $(0.22)$ \\
\hline
\end{tabular}




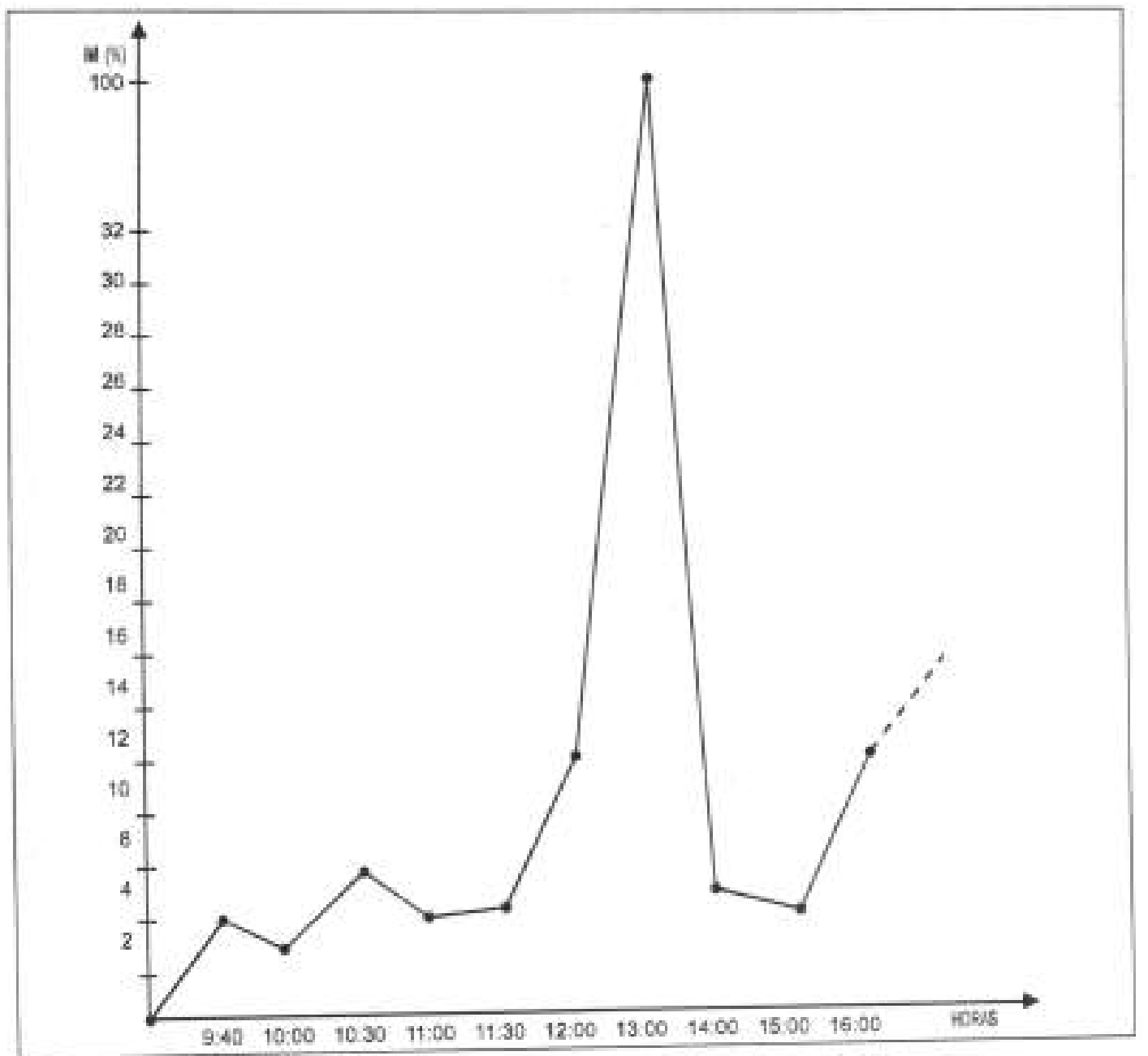

Grafico 2, Secuencia del cicio celular en 10 accesiones de Uthucus.

posible establecer que la mejor hora para la prefijación de las muestras con inhibidores mitóticos se encuentra comprendida entre las 10:00 am. y las 11;00 am. ya que se registran los mayores índices mitóticos $\left(\mathrm{F}^{\mathrm{M}}=27.23 \%\right.$, $\left.P_{11 \infty}=18.53 \%\right)$ (Cuadro 1 ).

El ciclo mitótico presenta una duración aproximada de 44 minutos (Cuadro 2), iniciándose este a las 10:00 am. y finalizando aproximadamente a las 10:44 am. (Grafico 1).

\section{IIL. DETERMINACION DEL INDICE MTTOTICO Y DURACION DEL CICLO CELULAR EN ULLUCUS.}

Autores: Talledo \& Escobar (1994-1995).

Colaboradores: Espinoza, A.; Arenas, N.; Alzamora. H.: Hayano, C.

(Inyestigación financiada por COTESU - CIP).

Mucstras procedentes del Departamento de Huánuco (PERU) fueron proporcionadas por el Programa Nacional de Recursas Genéticos y Biotecnología (PRONARGEB INIA). La temperatura durante el muestreo fue de $21^{\circ} \mathrm{C}$, la bumedad relativa $80-81 \%$.

La evaluación del número de células en división y del númeto de células hijas producidas a partir de las primeras en un periodo de tiempo de $6: 20$ horas en 10 accesiones de olluco $(16,27,34,37,43,45,47,59,74$ y 88$)$ permitio establecet que la mejor hora para la prefijación de las muestras a $21^{\circ} \mathrm{C}$ y $80-81 \% \mathrm{H}^{\prime}$ se encuentra entre las 12:00 pm. y las 13:00 horas ya que se registran los mayores indices mitóticos $\left(\mathrm{T}^{\mathrm{M}}{ }_{12 * 6}=11.43 \%, \mathrm{I}^{\mathrm{M}}{ }_{11000}=\right.$ $100.00 \%$ ) (Foto 2, Cuadro 3).

El ciclo mitótico presenta una duración aproximada de 1:00 hora (Cuadro 4), iniciándose a las 12:00 pm. y finalizando a las 13:00 (Gráfico 2).

\section{DISCUSION}

1. El trabajo de VERMA (1979) citado en resultados (cir. de Shmardyev et. al. 1988) nos indica que el nivel de ploidia no influyó sobre la duración del ciclo celular, mientras que las líneas de diferentes genotipos si se diferenciaban entre si para estos parámetros, lo que refleja el condicionamiento genótico de la duración del ciclo celular. Al respecto, es interesente setalar que para el maíz se han identificado más de 15 genes que actuan sobre este proceso (Shmarályev et al.; 1988) (Ver Anexo).

En especies de los géneros Licopersicon, Solanum y otros también se han identificado grupos de genes que 
ANEXO UNICO: Control Genético de la División Celular en Zea "maíz" (Tomado de Shmarajev et. al., 1988)

\begin{tabular}{|c|c|c|c|}
\hline Símb./Nombre Gen. & Cromosomas & Locus & Fenotipo \\
\hline $\begin{array}{l}\text { afd1-Absence of } \\
\text { firse div. }\end{array}$ & - & - & $\begin{array}{l}\text { Ausencia de la primera đivisión } \\
\text { de la meiosis. Esterilidad. }\end{array}$ \\
\hline am1 - Ameiotic. & ss & 20 & $\begin{array}{l}\text { Incapacidad para iniciar la } \\
\text { meiosis. Tejidos esporogénicos } \\
\text { degeneran. Esterilidad. }\end{array}$ \\
\hline as 1-Asynaptic, & is & 56 & $\begin{array}{l}\text { Ausencia de sinapsis de cromos. } \\
\text { homólogos en la profase } \\
\text { meiótica. Esterilidad parcial. }\end{array}$ \\
\hline $\begin{array}{l}\text { dsy1-Desynaptic. } \\
\text { dsy2--n- }\end{array}$ & - & - & $\begin{array}{l}\text { Desinapsis de los cromos. } \\
\text { homblogos. Total esterilidad } \sigma \text {, } \\
\text { parcial esterilidad Q. } \\
\text { Idem. }\end{array}$ \\
\hline $\begin{array}{l}\text { dv1-Divergent } \\
\text { spindle }\end{array}$ & - & - & $\begin{array}{l}\text { Huso divergente:sus filamentos } \\
\text { se separan en los polos en } \\
\text { meiosis I en } T I \text { se forman } \\
\text { micronucleos. }\end{array}$ \\
\hline dy1-Desynaptic & - & - & $\begin{array}{l}\text { Cromos. son incapaces de } \\
\text { conjugar en los microsporocitos }\end{array}$ \\
\hline ell-elongate & - & - & $\begin{array}{l}\text { Los cromos. se desespiralizan } \\
\text { y elongan en metafase y anafase } \\
\text { meiótica: formación de óvulos } \\
\text { sin reducir y óvulos haploides. }\end{array}$ \\
\hline $\begin{array}{l}\text { K10-Abnocmal } \\
\text {-chrom. } 10\end{array}$ & 10L & $\begin{array}{l}\text { Cerca } \\
\text { de } \\
\mathrm{sr2}\end{array}$ & $\begin{array}{l}\text { Engrosamiento heterocromático } \\
\text { al extremo del brazo largo del } \\
\text { cromos. 10. La actividad } \\
\text { nexcéntrica altera la segregación } \\
\text { normal. }\end{array}$ \\
\hline $\begin{array}{l}\text { ms4-male sterile } \\
\text { (=po1) }\end{array}$ & $6 S$ & 0 & $\begin{array}{l}\text { Esterilidad of mitosis post- } \\
\text { meiótica prematura, sin } \\
\text { replicación, anormal } \\
\text { microsporogénesic. }\end{array}$ \\
\hline ms28- -m- & - & - & $\begin{array}{l}\text { Bloqueo parcial o total de } \\
\text { citocinesis. }\end{array}$ \\
\hline ms43- - ar- & 8 & - & $\begin{array}{l}\text { Formación de polen pluri- } \\
\text { nucleado. }\end{array}$ \\
\hline $\begin{array}{l}\text { pam 1 - Plural } \\
\text { abnormalities } \\
\text { of meiosis. } \\
\text { pam2 - . - }\end{array}$ & - & - & $\begin{array}{l}\text { Moltiples anomalías inespect- } \\
\text { ficas antes y durante la } \\
\text { meiosis. } \\
\text { Idern a paml }\end{array}$ \\
\hline pol-Polymitotic. & $6 S$ & 0 & $\begin{array}{l}\text { Formación de núcleos beterogé. } \\
\text { neos en microsporas. }\end{array}$ \\
\hline stl-Sticky chrom. & 45 & 62 & $\begin{array}{l}\text { Cromos, apegados* en la meiosis. } \\
\text { Esterilidad parcial. }\end{array}$ \\
\hline
\end{tabular}


controlan los procesos de división celular (Rick, 1971; Zhuchenko, 1973; Ramanna, 1979) lo que sugiere que el control poligénico de la mitosis y la meiosis es universal.

II. En un estudio del Indice de fases $\mathrm{c}$ indice mitótico a una temperatura de $20^{\circ} \mathrm{C}\left( \pm 1^{\circ} \mathrm{C}\right.$ ) los autores (Talledo \& Escobar, 1995) encontramos que el ciclo mitótico para las 4 especies estudiadas del género Phaseolns tuvo una duración aproximada de 44 minutos.

Comparando estos resultados con los de Arenas N. y Hayano C. (1994), quienes registraron los indices mitóticos para dos de estas especies ( $P h$. aureus y $P h$. lunatus) a temperaturas superiores a los $22^{\circ} \mathrm{C}$ y determinaron que el ciclocelular en $P$ h. aureus fué de 2:30 horas y en $P h$. innatus de 2:00 horas, encontramos que la temperatura influye directamente sobre la duración del ciclo celular en las especies de este género.

III. La clasificación sistemática de Ullucus, que enfoca las accesiones de Ulluctus tuberosum como pertenecientes a una misma especie, indujo a los autores del presente trabajo a evaluar el indice mitótico a partir de 10 accesiones de olluco obteniendo los resultados presentados en los Cuadros $\mathrm{N}^{\circ} 3$ y $\mathrm{N}^{\circ} 4$. Sin embargo, al evaluar en forma discriminada 02 accesiones de Lepidium meyenii «acas (Crema y Crema-morada) procedentes del Departmento de Junin - PERU) hemos encontrado que entre éstas se presentan diferencias significativas, tanto en lo que se refiere al tamaño de las células como a sa volumen nuclear.

Estos resultados estarian indicando que las respuestas de estos 2 genotipos a un mismo tratamients citológico differen no sólo en lo que se refiere a la duración del ciclo celular, sino también en cuanto a caracteres cariomorfológicos. Corresponde a nuestros taxónomos determinar si estos criterios pueden ser suficientes para delimitar con mayor claridad la sistemática de este género.

Para ello debemos tener en cuenta que cuando enfocamos la especie como un sistema de formas debemos conocer todo el sistema de variabilidad (la amplitud de ta variabilidad genética de los diferentes earacteres). Los datos obtenidos experimentalmente sobre variabilidad genética inducida van a complicar aun más la serie de caracteres propias de las especies linneanas, evidenciando un cormplejo sistema de genotipos de las mismas y su potencialidad en el sentido de la diversificación especifica. Los earacteres morfofisiológicos sólo nos introducen hacia la comprensión de los genotipos, para un juicio concluyente sobre la naturaleza genética de las formas sc precisa del experimento (Vavilov, 1987). Es más, sabemos que la uniformidad externa no refleja to suficiente la composición genética de la especie o variedad, el establecimiento del sistema de la especie en el sentido de una serie completa de formas posibles puede precisar de la experiencia analítica y sintética del genetista. La sistemática moderna necesita de un enfoque genético para la comprensión de la especie (Vavilov,1987).
Vilbers (1979) senala que las diversas modificaciones estructurales de las especies son producidas por la información codificada en el genoma cuya activida puede estar condicionada por un programa autoinormo por señales ambientales.

Es necesario considerar qué factores ambientales, además de la luz, la temperatura y la duración del día, estarian desempeñando el rol de seîales ambientales.

\section{CONCLESIONES.}

1. El nivel de ploidia no influye sobre la duración del ciclo celular; sin embargo, las líneas de diferentes genotipos se diferencian entre sf para estos parámetros.

2. El desarrollo del ciclo celular está regulado por grupos de genes que controlan las fases que lo constituyen y por la acción de factores ambientales.

3. La acción de sef́ales ambientales como la luz, la temperatura, etc., puede influir sobre las variaciones de la duración del ciclo celular y de las peculiaridades estructurales de las especies. debido a su condicionamiento genético.

4. Esta información se codifica en el genoma, por lo que presentan especial importancia tanto los factores que actúan sobre el mismo como los que influyen sobre la capacidad de transcripción de dicha información.

5. Los grupos de organismos que se desarrollan en condiciones de aislamiento en hábitats que presentan diferentes variaciones ambientales, como es el caso de las especies que se desarrollan en la Zona Andina, se encueatran especialmente expuestos a dichos factores.

6. Los tratamientos propios de la reproducción y conservación por cultivos in vitro pueden estar modelando este proceso en forma parcial.

7. Este modelamiento explicaria la variación somaclonal registrada en algunos caso5.

8. Los estudios de la morfología cromosómica nos brindan informacion sobre el grado de sempaquetamiento* de la información genética $y$, a través de ello, de su capacidad de transcripción.

9. El condicionamiento genético del ciclo celular y su capacidad de respesta ante la acción de los factores ambientales pueden esclarecer el rol de la poliploidía en el proceso de diversificación específica de las ralces y tuberosas andinas, asi como los mecanismos de formación de poliploides.

10. Es importante desarrollar estudios del ciclo celular y de la morfología cromosónica en especies de rafices y tuberosas andinas.

\section{AGRADECIMIENTOS}

Los autores queremos expresar nuestro reconocimiento Programa Colaborativo COTESU-CIP, al 
CONCYTEC y a la Universidad Ricardo Palma, Rectorado, Facultad de Ciencias Biológicas y Departamento Académico de Ciencias, sin cuyo apoyo no hubiera sido posible desarrollar el presente trabajo.

\section{REFERENCLAS BIBLIOGRAFICAS.}

AL-BADER, A.A.; ORENGO, A.; RAO, P.N. 1978, G, phase-specific proteins of Hela cells. Proc. Nat. Acad. Sci. USA. 75: 6064-6068.

ARENAS , N; HAYANO, A. 1994. Estudio del ciclo celular en las especies Phaseolus hunatus y Phaseolus aureus.Lima, Perú. Libro de Resúmenes del $6^{\circ}$ Congreso de Jóvenes Cientificos (Marzo de 1994).

BARLOW, P.W. 1977. An experimental study of cell and nuclear growth and their relation to cell diversification within a plant tissue. Differentiation. \&: 153-157.

BARLOW, P.W. 1978. The interrelationship of the eycles of chromosome condensation and reduplication in cell growth processes. Nucleus. 21: 1-18.

BENNETT, M.D. 1972. Nuclear DNA content and minimum generation time in herbace ous plants. Proc. Roy. Soc. London B. 181: 109-135.

BOLKHOVSKIKH, Z; GRIF, $\mathrm{V}_{\text {; }}$ MATVEJEVA, T: ZAKHARYEVA, O. 1969. Chromosome numbers of flowering plants. Leningrad. Nauka $926 \mathrm{pp}$.

BRODSKY, V,Y: URIVAYEVA, IV, 1977. Cell polyploidy: its relation to tissue growth and function. Intem. Rev. Cyol. 50: 275-332.

BRODSKY, V.Y.; URIVAYEVA,I.V, 1981_(Poliploidía celular. Proliferación y diferenciación). Ed. Naúka, Moscú. (En ruso).

BROOKS, R.F. 1977. Continuous protein synthesis is required to maintain the probability of entry into $S$ phase. Cell. 12: 311-317.

BRUNORI, A. 1971. Synthesis of DNA and mitosis in relation to cell diferentiation in the roots of Vicia fabu and Latuca sativa. Canyologia, 24:209-215.

CÁRDENAS, M, HAWKES, J.G. 1948. Número de cromosomas de algunas plantas nativas cultivadas por los indios en los Andes. Cochabamba, Bolivia. Rev. Agriculsura $5 ; 30-32$.

D'AMATO, F, 1977. Nuclear cytology in relation to the development. Cambridge: Univ. Press.

DEL CAMPO, A., 1988. Biología del Ciclo de División celular. Maracaibo, Venezuela. Univ, de Zulia, Fac. Experimental de Ciencias, 151 pp.
ESCOBAR, C. 1991. Estudio cariotípico comparativo en cuatro especies del género Phaseolus; Ph. acutifolius Gray "Frijol tépary", $P h$. coccineus L. aFrijol ayocotes, $P h$ lunatus L. *Pallars y Ph. vulgaris L. *Frijol común. Tes. Lic. Biología. Universidad Ricardo Palma, Lima. 85 pp.

EPIFÁNOVA, O.L 1973, Estudio de los mecanismos de regulación del ciclo celular por medio de inhibidores de la transcripción y la translación. En: El ciclo celular). Ed. Naukka, Moscú. PP. 72-103, (En ruso).

FOARD, D.E. 1970. Differentiation in Plant Cells. In : Molecular and Structural Differentiation of Cells.

GROSSET, L, ODARTCHENKO,N. 1975a. Relationships between cell cycle duration, S-period and nuclear DNA content in erythroblasts of four vertebrate species. Cell and Tissue Kinet. 8: 81-90.

GROSSET, L.; ODARTCHENKO, N. 1975b. Duration of mitosis and separate mitotic phases compared to nuclear DNA content in erythroblasts of four vertebrate species. Cell and Tissue Kinet, 8; 91-96.

HERVAS, J.P. 1975. Mitotic activity of endopolyploid root cells in Allium cepa. Experientia. 31: 1143-1144.

IVANOV, V.B. 1974, (Bases celulares del crecimiento en vegetales). Ed. NaĹka, Moscú. 254 pp. (En ruso).

IVANOV, V.B. 1978. (Contenido de ADN nuclear y velocidad de desarrollo de las plantas). Ontogenes. T. 9. PP. 39-53.

JARDIN BOTANICO DE CORDOVA (Espana), 1992. Cultivos marginados: Otra perspectiva de 1492 . Colección FAO: Producción Agricola y protección vegetal. $N^{*} 26,339 \mathrm{p}$

IESIN, Y.E, 1967. (Tamaño nuclear y estado funcional de las celulas). Ed. Medicina, Moscú. 225 pp. (En ruso).

LARKKA, J, JOKELA, P. PIETILA, L., VIINIKKA, Y, 1992. Karyotypes and meiosis of cultivated and wild ulluco. Caryologia. $45:$ : 229-235.

LASSELAIN, M.J. PAREYRE, C; DEYSSON, G. 1978. Contribution to the understanding of the mechanism of cytokinesis in plant cells: the action of deoxiguanosine on the kinetics of a root metistem cell population. Cell and tiss. Kinet 11: 519.527.

LIBBENGA, K.R.;TORREY, J.G, 1973, Hormone induced endoreduplication prior to mitosis in cultured pea root cortex cells. Amer. J. Bot 60; 293-299.

L.IN, M.S; WALDEN, D.B, 1974. Endoreduplication induced by hydroxylamine sulfate in Zea mais root tip nuclei. Exp. Cell. Res.86: 47-52. 
MATTHYSSE, A.; TORREY, I. 1967. DNA synthesis in relation to polyploid mitosis in excised pea root segments cultured in vitro. Exp. Cell. Res,48: 484-499.

MEYER, J.R. 1945. Prefixing with paradiclaro-benzene to facilitate chromosome study Stain Tecnol.20: 121-125.

MEZIA, D. 1963. (La mitosis y la fisiologia de la division celular). Ed. Mir, Moscú. 345 pp. (En nuso).

MOLINA, M. DEL C. NARANIO, C.A. 1987. Cytogenetic studies in the genus Zea. 1. Evidences for five as the basic chromosome number. Theor. Appl. Genet. 73: 542-500.

MORRISON, J.W, 1953. Chromosome behaviour in wheat monosomics. Heredity. 7:203-217.

NAGL, W.1970. Differential inhibition by actinomycin D and histone $F_{1}$ of mitosis and endomitosis in Allium carinatum. Z. Pflanzenphysiol. Bd. 63: 316-326.

NAGL. W. 1978. Endopolyploidy and polyteny in differentiation and evolution. Amsterdam: North-Holland. NAGL, W.: PESCHKE, C, VAN GYSEGHEM, R. 1976, Heterochromatin underreduplication in Tropaeolum embryogenesis. Naturwissenschaften. Bd, 63: 198-199. National Research Council, 1989. Lost crops of the Incas: Little-Known plants of the Andes with Promise for Worldwide Cultivation. National Academy Press, Washington, D.C. 415 pp.

NUTI RONCHI, V.; AVANZI, S; D'AMATO.F. 1965. Chromosome endoreduplication (endopolyploidy) in Pea root meristems induced by 8-azaguanine. Caryologia. 18 : 599-617.

O'MARA, J.G, 1939, Obsiervations of the inmediate effects of colchicine. J. Herd 30: 35-37.

PIINACKER, L.P.; SREE RAMULU, K.; DIJKHUIS, P.; FERWERDA, M.1989. Flow cytometric and karyological analysis of polysomaty and polyploidization during callus formation from leaf segments of various potato genotypes. Theor. Appl. Genet 77:102-110.

PRESCOTT, D.M. 1976. Reproduction of eukaryotic cells. N.Y, L. Acad. Press.

PROKOFIEVA-BELGOVSKAYA.A. 959. (Interacciones del núcleo y el citoplasma en células de almacenamiento de almudón en papa). Citologia, T. 1. PP. 257-269. (En ruso).

PROKOFIEVA-BELGOVSKAYA. A.A. 1960. (Ciclo naclear y diferenciación de las celulas somaticas. En: Problemas de la Citologia y la Fisiologia General). Ed Ac deCC. de la URSS, Moscú, Leningrado. PP. 215-253. (Ennuso).
PROKOFIEVA-BELGOVSKAYA, A.A. 1986. (Regiones heterocromáticas de los cromosomas). Ed. Naúka, Mosc6. 431 pp, (En ruso).

RAMANNA, MS, 1979. A re-examination of the mechanisms of $2 \mathrm{n}$-gamete formation in potato and its implication for breeding. Euphytica. 28: 537-561.

RAO, PN: WILSON, B.A.; SUNKARA, P. 1978. Inducers of DNA synthesis present during mitosis of mammalian cells lacking $\mathrm{G}_{1}$ and $\mathrm{G}_{2}$ phases. Proc. Nat. Acad Sci USA. 75: 5043-5047.

RICK. C.M. 1971. Some Cytogenetic Features of the Genome in Diploid Plant Species. Strabler Symp., 1,2.

SHIOMI, T; SATO, A.1978. Cell cycle studies in a temperature-sensitive cell division mutant of mammalian cells. Cell. Struct. and Funct. 3: 95-102.

SHMARAYEV, G. E; PODOLSKAYA, A.P.; GOLUBOVSKAYA, 1.N, 1988. (Genética del maíz En: Genética de las plantas cultivadas), Leningrado, Agropromizdat. PP, 6-67.(En ruso).

SINNOTT, E.W. 1960. Plant morphogenesis. N.Y.: McGrow-Hill Book Co. Inc.

SMIRNOV, V.G. 1991. (Citogenética). Ed. Vysshaya shkola. Moscú: $247 \mathrm{pp}$.

SMITH, B.J.; WIGGLESWORTH, N.M. 1972. A cell line wich is temperature-sensitive for cytokinesis. J. Cell. Physiol. 80: 253-258:

STEPHEN,1. 1973. Occurrence of polyteny, endoplyploidy nd numerical variation of nucleoli in maize endosperm. Sci. and Cult. 37: 323-324.

SIEPHEN, L. 1974. Cytological investigation on the endosperm of Borassus flabellifer. Cytologia.39: 195-207.

TALLEDO, D.1991. (Estudio cariotípico comparativo de 9 especies del género Solanum L. utilizadas en el Fitomejotamiento como donantes de caracteres de impottancia económica). Tesis Diss. Ph. D. in Biology. Moscú. 152 pp. (En ruso).

TALLEDO, D; ESCOBAR, C., 1995. Caracterización cariotípica en 4 especies del género Phaseolus, Lima, Universidad Ricardo Palma. Inf. cientifica, 55 p.

TALLFDO, D.; ESCOBAR, C.; ALLEMAN, V. 1993. Introducción al análisis cromosómico en vegetales. Lima, Universidad Ricardo Palma. 141 pp.

TJO, J.M.: LEVAN, A. 1950. The use of oxyquinoline in chromosome analysis. An. Estac. Exp. Aula Del. 2, 21. 
TJO, J.H.; LEVAN A.1954. Some experiences with acetic-orcein. An. Estac. Exp. Aula Dei. 3:225-228.

VAN PARUS, R.; VANDENDRIESSCHE, L. 1966. Changes in the DNA content of nuclei during the procces of cell elongation in plants. I. Fomation of polytene chromosomes. Arch. Intern. Physiol. Biochem. 74: 579.586.

VAN'T HOFF, J. 1973. The regulation of the cell division in higuer plants. From: Basic Mechanisms in Plant Morphogenesis. Brookhaven Symposium. PP. 152-165.

VAN'THOFF, J, SPARROW, A.M. 1963, A relationship between DNA content, nuclear volume and minimum mitotic cycle time. Proc. Nat. Acad. Sci. USA. 49;897-902.

VAVILOV, N.1. 1987, (Métodos para identificar los Centros de Origen de las plantas. En: Origen y geografia de las plantas cultivadas). Leningrado, Nauka. PP, 32-45. (En ruso).
VILIIERS, T.A. 1979. Reposo y supervivencia de las plantas. Barcelona, Ed. Omega. 77 p.

WANG, R.I. 1974. Temperature-sensitive mammalian cell line blocked in mitosis. Nature. 248:76-78.

WANG, R.I. 1976. A novel temperature-sensitive mammalian cell line exhbiting defective prophase progression. Cell. 8: 257-261.

WISSINGER, W; WANG, R.I. 1978. A temperaturesensitive cell line defective in post-metaphase chromosome movement, Exp. Cell Res. 112: 89-94,

ZHUCHENKO,A.A. 1973. Caracterización citogenética. En: (Genética de los tomates). Kishiñov (Moldavia), Shtiintza. PP. 82-156. (en ruso) 